\title{
Ronald Coase's Method of Building More Realistic Models of Choice
}

\author{
Bingyuang Hsiung ${ }^{1} \&$ J. PAtrick Gunning ${ }^{2}$ \\ ${ }^{1}$ Department of Economics, National Taiwan University, Taipei, \\ Taiwan, People's Republic of China \\ ${ }^{2}$ College of Arts and Sciences, American University of Sharjah, \\ PO Box 26666, Sharjah, United Arab Emirates
}

This paper argues that Ronald Coase's major contributions to economic theory are best understood in terms of the distinct method he used to build more realistic models of choice. We call his method the benchmark-comparison method. It consists of building models of choice and then using them as benchmarks in the further investigation of economic interaction, either by comparing the benchmark models with observed interaction or by building additional models of choice, which may themselves function as benchmarks. The paper first describes the method then demonstrates how Coase used it in his two most famous papers. We go on to show how an understanding of the method confirms Coase's own statements about the continuity of his thought. Finally, we assess Coase's critique of Milton Friedman's positivist methodology and discuss a recent paper on Coase's methodology.

\section{Introduction}

This paper argues that a useful way to understand Ronald Coase's contributions to economic theory is to identify the distinct method he used to build more realistic models of choice. We call his method the benchmark-comparison method. It consists of building models of choice that serve as benchmarks in the further investigation of economic interaction. The further investigation entails comparing the benchmark models with observed interaction and building additional models of choice, which may themselves function as benchmarks. In his two most famous papers, Coase $(1937,1960)$ applied this method at two levels of aggregation. At the first level, the number of interactors is small, as in the classic dyads of the employer-employee and farmer-rancher; the second level concerns large numbers of interactors, as in the equilibrium models of the market economy. We show how he used the method in both of these cases.

It is necessary at the outset to dispel some misconceptions that may arise from a cursory reading of what Coase has written about the logic of choice. Alluding to Gary Becker's work on the economic approach to human behavior (Becker, 1976), Coase has criticized economics for its sterile models of choice. $\mathrm{He}$ writes that this approach is so far out of touch with reality that it can 
rightfully be applied to rats, cats and octopi (Coase, 1988, p. 3). ${ }^{1}$ Coase is not criticizing the use of choice models per se, but rather Becker's simplistic definition of choice. In Becker-type optimizing models, 'The consumer is not a human being but a consistent set of preferences' (Coase, 1988, p. 3), while the firm 'is effectively defined as a cost curve and a demand curve, and the theory is simply the logic of optimal pricing and output combinations' (Slater, 1980, p. ix; quoted by Coase, 1988, p. 3). Coase acknowledges that 'existing economic theory embodies the logic of choice and is of wide applicability ....' His project is to "employ this economic theory to examine the role which the firm, the market, and the law play in the working of the economic system' (Coase, 1988, p. 5). What is required is 'a theoretical system capable of analyzing the effects of changes in these arrangements. To do this, it is not necessary to abandon standard economic theory, but it does mean incorporating transactions costs into the analysis' (Coase, 1988, p. 30). Since Coase defines transactions costs in terms of the alternatives that agents would have to forego, his point here is that economic theory ought to specify these alternatives and include them in its models of choice.

A second misconception is that Coase's criticism of economic theory is based on the view that individuals are not always choosers. Richard Zerbe \& Steven Medema, for example, place Coase's method in what they call the British tradition, which

emphasizes understanding, rather than prediction, as the first function of theory. It stresses the use of inductive methodology in the building of theory rather than the development of a theory largely by deductive means. The focus on induction in turn leads to an emphasis on the understanding of the behavior of individuals and institutions rather than their treatment as black boxes which carry out certain functions. (Zerbe \& Medema, 1997, p. 210)

In a footnote they define 'understanding' as 'the knowledge of the underlying structures and causal mechanisms of the economic system and their role in generating economic outcomes' (Zerbe \& Medema, 1997, p. 232, n. 5).

Zerbe \& Medema assert that traditional neoclassical models of the economic system are unrealistic because they only employ rational choice models. When they write about the importance of understanding the behavior of individuals and institutions, they are not referring only to understanding the chosen behavior and to the chosen institutions, such as Coase's firm. They argue that to understand behavior, one must employ findings from psychology, and that to understand institutions, one must employ a concept of institution s that transcends the assumption that the institution is a means that rational actors choose in order to minimize transactions costs. ${ }^{2}$ On the basis of our reading of Coase's work, we believe that he never made such an assertion. In his economic system, as we

\footnotetext{
${ }^{1}$ See also Coase's discussion of Becker's work in Coase (1978). A comparison of Coase and Becker is presented in Hsiung (2001).

${ }^{2}$ They assert that 'Many of the shortcomings of the economic model of individual behavior have been pointed out by psychologists, for which we should be grateful but chagrined' (Zerbe \& Medema, 1997, p. 212).
} 
shall see, agents are assumed to make choices. Coase criticizes the standard models of the economic system and government action as unrealistic because they do not include the choices and alternatives that economic actors really face.

Finally, it is also worthwhile to note that there is no reason to believe that Coase is deeply interested in methodological issues. His position on method is straightforward and simple: all that is needed to do good economics is the appropriate mix of theory and reality. ${ }^{3}$ Since transactions costs and the institutions that deal with them are part of reality, we should recognize this. He accepts standard economic theory as an appropriate way of doing this, but he does not reflect deeply on economic method, nor does he put his own method under the microscope, as we aim to do here. ${ }^{4}$

Section 2 of this paper describes the benchmark-comparison method-the method that we claim Coase employed. Section 3 shows how he used it at the level of small numbers interaction, while Section 4 shows how he used it to deal with interaction in the economic system. Section 5 explores Coase's hypotheses about the development of his thought. He has asserted a continuity in his theoretical work during the 50-odd years that he has been writing. We affirm this continuity and attribute it mainly to his use of the benchmark-comparison approach to build increasingly complex, yet more realistic, models of economic interaction.

\section{The Benchmark-Comparison Method}

The benchmark-comparison method appears to be used in all science and, indeed, in all rational thought. However, we do not intend to deal with it from an epistemological perspective. Its relevance to Coase's contributions stems from the fact that it is commonly used for building models of choice. The basic model in this field is that of the rational actor, who possesses limited means for achieving his ends and, as a consequence, must make choices. ${ }^{5}$ The model of the solitary rational actor functions as a benchmark for building a model of the interaction of two rational actors. In the latter model, the alternatives available to each agent depend on the choices that are made by the other. We compare the benchmark with what we can understand about the choices of individuals in two-person interaction. We use what we learn from our comparison as a basis for building a model of each actor's choice in the two-person context.

What does this two-person model look like? If we make some conventional assumptions about preference orderings, homogeneity and divisibility, one possibility is the model represented by the Edgeworth-Bowley diagram. This diagram

\footnotetext{
${ }^{3}$ He defines economics by referring to its subject matter, not to its method, favoring Lionel Robbins's definition of economics as 'the science which studies human behaviour as a relationship between ends and scarce means which have alternative uses' (Robbins, 1932, p. 15; see Coase, 1978, p. 201). ${ }^{4}$ In 'Marshall on method' Coase (1975, p. 175) approvingly attributes to Marshall a lack of interest in method.

${ }^{5}$ A realistic model of choice must take account of time and uncertainty. Coase, however, was not concerned with these limitations of the rational actor model; he generally assumes timelessness and certainty, and we shall follow his lead.
} 
assumes an initial distribution of two goods and describes the possible outcomes under the assumption that each aims to reach her highest level of utility. This two-person model can be used as a benchmark for building more complex models. One example is the general equilibrium model that Francis Bator used in his simple exposition of modern welfare economics (Bator, 1957). Bator compared the benchmark Edgeworth-Bowley model with a part of what we know from experience and intuition about many-person interaction; his production possibilities frontier and utilities possibilities frontier correspond to the contract curve in the Edgeworth-Bowley box.

The benchmark-comparison method can be used to build models of economic interaction between producer-sellers and buyers in a particular market. We begin by assuming that the economy contains two goods, as in the EdgeworthBowley model. The difference is that one of them is money. If we assume also that there is only one producer-seller who has already produced a given quantity of the good, we can build a bidding model in which competition among buyers drives the price up to the level at which the quantity demanded by the highest bidders equals the quantity that was produced. This simple bidding model can be used as a benchmark for a model of zero-cost monopoly supply by assuming that the producer must choose a level of output, that he maximizes profit, and that the demand curve is linear. A model built on these assumptions yields a profit-maximizing price corresponding to the point on the demand line at which the price elasticity of demand is one. By extension, one can use the benchmarkcomparison method to build models of different kinds of market structures assuming positive production costs. ${ }^{6}$

It should be evident that the benchmark-comparison method described here is nothing new. Economists who build rational choice models have always utilized it, albeit intuitively. We shall argue that Coase's inventive application of this method is precisely what enabled him to arrive at his noteworthy contributions to economics, and that the continuity in Coase's thought is best understood in this light.

\section{Use of the Method to Build Models of Two-Person Exchange}

Coase's use of the benchmark-comparison method in his two most important papers can be divided into two classes: two-person (and other small number) exchange benchmarks and economy-level benchmarks. He used two-person exchange benchmarks to help describe interactions that he later incorporated into his models of the market economy. In this section, we discuss the two-person exchange benchmarks.

\footnotetext{
${ }^{6}$ We do not mean to assert historical precedent for the Edgeworth-Bowley model. There is no reason to believe that economists who invented the initial models of monopoly and competitive markets ever conceived of the Edgeworth-Bowley model. The benchmark-comparison method of building models is not the only method. In the case of Coase, however, it is interesting to note that he surmises that the Edgeworth-Bowley model, which implicitly assumes zero transactions costs, may have played a subconscious role in the development of his positive transactions cost model of interaction (Coase, 1988, p. 169).
} 


\subsection{The Nature of the Firm}

An examination of Coase's theory of the firm shows that he began with a model of an individual's choice and then expanded on this by comparing it with three successive dyads. He began with an individual who faced a choice of where to allow her factor to be employed in a model of zero transaction costs. Recognizing the costs of making exchanges, he built a model of a dyad in which the employer and factor owner faced positive transactions costs. He then used this as a benchmark for building a model of the employer-employee relationship, or firm. Finally, he contrasted the latter relationship with another dyad-the master-slave relationship.

The choice of where to employ a factor corresponds to what he called the allocation of factors by means of the 'price mechanism':

[I]n economic theory we find that the allocation of the factors of production between different uses is determined by the price mechanism. The price of factor $\mathrm{A}$ becomes higher in $\mathrm{X}$ than in $\mathrm{Y}$. As a result, $\mathrm{A}$ moves from $\mathrm{Y}$ to $\mathrm{X}$ until the difference between the prices in $\mathrm{X}$ and $\mathrm{Y}$, except in so far as it compensates for other differential advantages, disappears. (Coase, 1937, p. 35)

He uses this as a benchmark for building the first dyad model-the positive-cost exchange. In this model, positive cost exchanges are necessary to allocate factors in a real market economy. Coase defines these exchange costs by contrasting the zero-cost allocation with his image of the exchange of factors as it occurs 'in reality'. This enables him to identify what he calls the costs of using the price mechanism: (1) the costs 'of discovering what the relevant prices are'; (2) the 'costs of negotiating and concluding a separate contract for each exchange transaction'; and (3) the costs associated with making long-term contracts (Coase, 1937, pp. 38-40). ${ }^{7}$

Coase's listing of the costs of exchange is a preliminary exercise designed to help him build the second dyad, which uses the first dyad as a benchmark. This is a contract

whereby the factor, for a certain remuneration (which may be fixed or fluctuating), agrees to obey the directions of an entrepreneur within certain limits. The essence of the contract is that it should only state the limits to the powers of the entrepreneur [employer]. Within these limits, he can therefore direct the other factors of production. (Coase, 1937, p. 39)

He calls the allocation of factors by means of contracts such as this, the firm. He contrasts allocation by means of the firm with allocation by means of the price mechanism. Outside the firm, 'price movements direct production, which is co-ordinated through a series of exchange transactions on the market' (Coase, 1937, p. 35). Inside the firm, a 'factor of production (or the owner thereof) does not have to make a series of contracts with the factors with whom he is co-operating ... as would be necessary, of course, if this co-operation were as a direct result of the working of the price mechanism' (Coase, 1937, p. 39). He goes on to argue that 'a firm will tend to expand until the costs of organizing an extra transaction within the firm become equal to the costs of carrying out the

\footnotetext{
${ }^{7}$ Coase later de-emphasized the third of these costs (Coase, 1937, pp. 67-69).
} 
same transaction by means of an exchange on the open market or the costs of organizing another firm' (Coase, 1937, p. 44). His aim, according to his reflections over 40 years later, was to account for individuals' choices among contractual relationships, given the reality of costs of making exchanges (Coase, 1991, pp. 56-58).

The third dyad is that of the master-slave, in which the entrepreneur's powers to give orders are not limited (Coase, 1937, pp. 39, 53-54). His purpose in introducing this relationship is to highlight the limited powers of the employer over the employee in the relationship that comprises the firm. Thus, the master-slave relationship is used as a benchmark to underscore the voluntary nature of the employer-employee relationship.

Recently, Coase has extended his discussion and, in the process, has provided hints of a more elaborate model. He suggests that what he had in mind regarding the firm was an arrangement of production that 'takes place without the need for bargains between the owners of the factors of production.' Instead, the firm acquires legal rights to the use of the factors of production that enable it to arrange production by means of an administrative decision. Thus the 'alternative to an interfirm transaction is to bring it within the purview of a firm...' He goes on to emphasize an element that he omitted in his earlier paper, namely, that the firm emerges 'only when the organizer has contracts with several factors whose activities he coordinates' (Coase, 1991, pp. 66-68). He thereby extends what was previously a dyad contract model into one of a contract between the organizer and the initial owners of several factors. In this extension, the dyad contract model functions as a benchmark for the model that includes owners of several factors.

We see from this discussion that the zero-transactions cost dyad functions as a benchmark for the positive-transactions cost dyad; that the positivetransactions cost dyad functions as a benchmark for the employer-employee dyad; that the master-slave dyad functions as a benchmark for helping to understand the voluntary nature of the employer-employee dyad; and that the employer-employee dyad functions as a benchmark for the model of an employer who hires several factors.

\subsection{Social Cost}

Coase begins his 1960 paper with an extended discussion of the farmer-rancher transaction, in which the rancher's straying cattle destroy the farmer's crops. He shows that under the assumption of zero transactions costs, regardless of who owns the right to control the rancher's action of allowing the cattle to stray, 'the final result would be the same and would maximize the value of production.' There is 'no long-run effect on the allocation of resources' (Coase, 1960, pp. 101-102). This final result is achieved by means of exchange, if it is necessary. Coase later wrote that his aim in using the unrealistic zero transactions cost model 'was not to describe what life would be like in such a world but to provide a simple setting in which to develop the analysis and, what was even more important, to make clear the fundamental role which transaction costs do, and should, play in the fashioning of the institutions which make up the 
economic system' (Coase, 1988, p. 13). In his theory of the firm, Coase's use of the zero exchange cost model as a benchmark had to be inferred from his use of the employment choice as a benchmark. Here, he states outright that the zero transactions cost model is a benchmark that he used to derive the role of the institution s in the economic system.

Having identified the implications of the benchmark zero-cost transactions model, he goes on to consider transactions under realistic conditions. To do this he presents a series of four real legal cases that contain external effects of the farmer-rancher type. He compares the rulings in each of these with the outcome of the benchmark case in order to demonstrate that because of the presence of transactions costs, the judge or an outside evaluator of a case might have cause to believe either that the exchange required to maximize the value of production would not occur, or that if it were to occur, it would entail substantial costs. Under these conditions, it is possible that other forms of organization, by which he means the firm and government, would be superior to the market in utilizing resources (ibid., p. 115). Having already discussed the firm in his 1937 paper (p. 117), he focuses here on government organizations.

For the two-person case, Coase does not recommend any specific government action. Instead, he proceeds to use the two-person positive transactions costs model as a benchmark for analyzing a more complex case, one that involves a number of parties. First, he discusses the case of a smoke nuisance, suggesting that as the number of parties involved increases, transaction costs may prevent the parties from reaching a voluntary agreement and that, under this circumstance, governmental regulation is a possible solution (Coase, 1960, pp. 116-117). Then he considers the case of Adams v. Ursell, where a fried fish shop was set up near houses of 'a much better character' (Coase, 1960, p. 123). In this case the court issued an injunction against the fish shop. Finally, he considers the case of Delta Air Corporation v. Kersey, Kersey v. City of Atlanta, a case involving the airport and the residents living nearby. In this case, the court allowed the airport to continue to be noisy and to spew out dust but enjoined it from allowing its planes to fly too low on the reasoning that this external effect could be cheaply avoided (Coase, 1960, pp. 128-131).

We see two uses of the benchmark-comparison method here. First the zero transactions cost, two-person exchange is used as a benchmark to build an image of two-person exchange under the assumption of positive transactions costs. Second, the two-person case is used as a benchmark for building a model of a many-person case. It is with respect to the latter case that Coase seems to believe that some sort of government intervention may be warranted.

\section{Use of the Method to Build Models of an Economy}

In this section, we demonstrate Coase's use of the benchmark-comparison method to model economic systems. Here he begins with simple models and proceeds to incorporate the costs of making transactions, institutions that are created as a means of reducing or avoiding these costs, and government institutions to which economists might assign the task of correcting problems associated with external effects. 


\subsection{The Nature of the Firm}

In his paper on the firm, Coase makes reference to Arthur Salter's model of an economic system in which 'supply is adjusted to demand, by a process that is automatic, elastic and responsive' (Coase, 1937, p. 34). The methodological foundation for models such as Salter's may be traced to John B. Clark's so-called static state, in which the same production, buying and selling, consumption and saving behavior in a set of markets is repeated again and again (Clark, 1899a, Chapter 3; 1899b). There is no change and no real time, although time is simulated by the hypothetical, repeated behavior.

Clark's static state might be considered a benchmark for Salter's model. The static state is a model in which supply is fully adjusted to demand in all markets. Starting with this model, we use our intuition and experience to contemplate a variety of changes in demand or cost conditions which, if they are not immediately accommodated, would lead to a situation in which supply is not adjusted to demand. We proceed to catalogue these changes. Then we assume that the catalogued changes are occurring continuously. At the same time, we assume that all agents instantaneously identify and adjust to them. In this way, we can conceive the Salter model as a Clarkian static state that is continuously disarranged by changes in the conditions of demand and supply, whereupon a new static state is established that reflects these changed conditions. The model's conception of equilibrium is identical to that of new classical economics.

Coase uses the Salter model as a benchmark for building his own, more complex model. He begins by interpreting the automatic adjustment mechanism as a process that entails no price mechanism costs, in the sense outlined in Section 3.1 above. In this interpretation he characterizes Salter's model as an 'incomplete' image of the economic system that fails to capture what happens 'within a firm'. A workman within a firm does not automatically adjust to a change in demand as he would if he were an independent contractor; instead, he follows the instructions of his boss (Coase, 1937, p. 35). Coase points out that when we take account of the costs of using the price mechanism, two kinds of coordination become evident: the sort that occurs in the Salter model and the kind associated with the entrepreneur. Thus, one can say that Coase developed a new classical equilibrium model in which the concept of the entrepreneur, as exhibited by the employer-employee relationship, embodies all the organization or coordination that occurs outside of the Salter model. The presence of transactions costs gives entrepreneurs incentives to form firms. A firm, which consists of a contract with employees in which the latter agree to shift their work from one project or location or type to another without requiring a new contract, enables entrepreneurs to avoid the costs of using the price system (or to circumvent the full impact of these costs).

Like the Salter model, Coase's model contains automatic and instantaneous adjustment to change. The difference is that some of the automatic and instantaneous adjustment takes place in firms, as employers alter their instructions to employees without negotiating a new contract. Moreover, the Coase model includes the formation of new firms and, one must assume, the breaking 
up of existing firms by means of instantaneous adjustments to changes in transactions costs.

Recently, Coase has extended his model by recognizing a substitution relationship between vertical integration and firm-to-firm transactions (Coase, 1991, pp. 65-67). In making this extension, he uses his own 1937 model as a benchmark for his newer model. In his recent reflections on this work, he points out:

The analysis cannot be confined to what happens within a single firm. The costs of coordination within a firm and the level of transaction costs that it faces are affected by its ability to purchase inputs from other firms, and their ability to supply these inputs depends in part on their costs of coordination and the level of transaction costs that they face, which are similarly affected by what these are in still other firms. What we are dealing with is a complex interrelated structure. (Coase, 1995, p. 245)

Presumably, the instantaneous adjustments in the expanded model would include choices by business units to merge and divide, and agreements among firms to alter the nature and amount of firm-to-firm transactions. This quote also suggests that even though Coase has never explicitly acknowledged and therefore may not be aware of the use of benchmarks in his thought, they nevertheless play an important part in it.

\subsection{Social Cost}

In his 1960 paper, Coase begins with the Salter model and quickly introduces the firms of his 1937 paper. Then he proceeds to extend the model. To see how he accomplishes this, consider his assumption that firms arise because coordination by means of the employer-employee compact is superior, under some circumstances, to coordination by means of the price system. On analogous reasoning he introduces three possible ways that government action may improve matters. First, he considers the courts in their handling of nuisance law: 'In a world in which there are costs of rearranging the rights established by the legal system, the courts, in cases relating to nuisance, are, in effect making a decision on the economic problem and determining how resources are to be employed' (Coase, 1960, pp. 132-133). Secondly, he considers statutory enactments. Statutory enactments affect the delimitation of rights (Coase, 1960, p. 133). Thirdly, he discusses regulation. He writes that organization by means of government regulation may sometimes be superior.

Instead of instituting a legal system of rights which can be modified by transactions on the market, the government may impose regulations which state what people must or must not do and which have to be obeyed.... The government is able, if it wishes, to avoid the market altogether, which a firm can never do.... [Although] direct governmental regulation will not necessarily give better results than leaving the problem to be solved by the market or the firm ... there is no reason why, on occasion, such governmental administrative regulation should not lead to an improvement in economic efficiency. (Coase, 1960, pp. 117-118)

We see from these statements a broader vision than was evident in his paper on 
the firm. He expands the 1937 model to include the possibilities that the courts may change legal rights, that the legislature may enact laws, and that the legislative or administrative arm of government may impose regulations.

Although he does not again refer to the instantaneous adjustment of the Salter equilibrium, his reference to firms in the above quotation and his recent discussion of the continuity of his thought suggest that he conceives of his new model in this way also. Thus, any change in property titles or direct regulation is incorporated with the other changes in the conditions of demand and supply. All such changes trigger immediate adjustments through the price mechanism and within firms. Adding these 'variables' in the choice calculus to those that have already been added on the basis of Coase's 1937 paper on the firm complicates the initial Salter model quite a bit. A full presentation is beyond the scope of this paper. It is sufficient to point out some examples of choices that would presumably be included. First, regulatory agencies would presumably try to take account of the market and firm adjustments that are likely to occur as a consequence, or even in anticipation of, some regulatory actions. Secondly, managers of firms would presumably try to take account of responses to, and anticipation s of, their actions on the part of courts, the legislature and regulatory agencies. Thirdly, courts would presumably try to take account of how their decisions are likely to affect and be anticipated by the legislators in their decisions to delimit rights. A new classical equilibrium model that included all of these elements would be complex indeed. The point to be emphasized here, however, is that in blazing the trail toward the building of such a model, Coase systematically employed the benchmark-comparison method.

\subsection{Fundamental Alterations in the Salter Equilibrium}

We could end the discussion of Coase's models here if his critique of Pigou had not led him to question the implicit assumption of the Salter model—or, more generally, of neoclassical economics - that entitlements refer to the rights to own and use real, tangible property. One of the most important contributions of the Coase's social cost paper was his recognition that to deal properly with the problem of external effects, one ought to frame the analysis not in terms of physical factors of production but in terms of rights 'to perform certain (physical) actions' (1960, p. 155). In other words, one should define a factor of production not in physical terms but in terms of the rights to act in certain ways. Defining it in these terms helps us form a clearer understanding of the opportunity cost concept: 'The cost of exercising a right (of using a factor of production) is always the loss which is suffered elsewhere (in consequence of the exercise of that right) - the inability to cross land, to park a car, to build a house, to enjoy a view, to have peace and quiet or to breathe clean air' (Coase, 1960). Coase's point is that the notion of a physical factor of production should be replaced by the notion of a right to act in a particular way, including a way that has external effects (see Gunning, 2000a, 2000b). Like the physical factors of production and like consumers' goods, these rights are exchangeable.

This conception of the choices faced by actors in the economic system may explain how Coase came to view the entrepreneur's production of institution s as 
part of the market process. The relevance of Coase's exchange costs and transaction costs become evident when Salter's notion of equilibrium is applied to the trading of rights to command actions instead of physical factors of production. The creativity of the human actor in producing institutions becomes important as soon as one realizes that the production of particular configurations of rights reduces the costs of transactions and helps to solve incentive problems. It is this insight that makes up the bulk of Coase's legacy, as expressed in the work of writers such as Armen Alchian, Benjamin Klein and Harold Demsetz. Thus, while Coase used a benchmark-comparison methodology that is comparable to that of other economists, he used it in a new way.

\section{The Continuity of Coase's Thought}

We have suggested that there is a continuity in the development of Coase's thinking about the market economy. The source of this continuity is his consistent use of the benchmark-comparison method of building more realistic models of economic choice. A concern in both of his major papers is whether neoclassical models of choice are relevant to the problems economists want to address. To deal with this concern, he employs the benchmark-comparison method. In his paper on the firm, he uses this method first to expand the traditional Edgeworth-Bowley choice model to include the employment relation and then to expand the Salter equilibrium to cover an economy with costs of using the price mechanism. He asks whether the traditional models of choice reflect the choices that real actors make. His answer is yes but only up to a point. They neglect alternatives that Coase's intuition and experience reveal to him are important. When he compares the benchmarks with his own insight into the alternatives faced by real actors, he discovers (1) the potential gain from the employment agreement that specifies the employees' tasks only within broad limits and (2) the costs of using the market mechanism. He uses these discoveries to expand the traditional models so that they include additional alternatives.

In the social cost paper, the problem is to represent realistically public policy choices and the choices of the market participants affected by them. As before, he employs the existing models as benchmarks. This time his insight helps him identify choices of market participants in response to a particular set of rights to control actions, and choices of policy regulators, judges and legislators. Regarding market participants, he discovers that they can "contract around' an initial delimitation of rights. This suggests to him that, in the zero-transaction s costs world, resource use (i.e. the actions performed by agents in the production of goods) will be the same under any initial delimitation of rights. Regarding policy choices, he recognizes how the various types of state-controlle d coercion are related to each other. Most importantly, the effects of each can be best understood by considering the intervention as a delimitation of rights to act in particular ways.

The most important elements of Coase's life work represent two successive expansions of the fundamental neoclassical model of choice, with the earlier expansion functioning partly as a benchmark for the later expansion. Seen in this 
light, his social cost paper is a natural extension of his paper on the firm. His 1937 paper also contains a glimpse of his later idea of defining a factor of production as a right to control actions. Consider the problem Coase faced. In economic theory, the concept of a 'factor of production' includes all marketable inputs into the production process. In traditional theory, these were the material inputs land, labor, and capital equipment. Yet Coase had observed that the entrepreneur regards the right to control another person's action, within limits, as valuable. How can this fact be incorporated into the theoretical framework of economics? The answer is to change radically the concept of a factor of production so that it means rights to control actions.

\section{Conclusions}

We have described how Coase used what we call the benchmark-comparison method to identify shortcomings of the typical models of (1) the employeremployee relationship, (2) the adjustment of the actors to a change in the delimitation of rights, (3) the market mechanism and (4) government intervention in the price system. We also showed how he incorporated his discoveries into existing models to build more comprehensive models that can themselves serve as benchmarks. Our assumption that he used the benchmark-comparison method enabled us to affirm Coase's claim about the continuity in his thought. Finally, we showed how our interpretation was consistent with Coase's own discussion of methodological issues.

Our aim has been to demonstrate the usefulness of the benchmarkcomparison method in comprehending Coase's contributions to economics. We also believe that the method is useful for understanding a much broader set of economic ideas, including developments in post-Keynesian economics, public choice theory, constitutional economics and, of course, the various traditions that have evolved from the work of Coase himself.

\section{References}

Bator, F. M. (1957) The simple analytics of welfare maximization, American Economic Review, 47, pp. 22-59.

Becker, G. (1976) An Economic Approach to Human Behavior (Chicago, University of Chicago Press).

Chamberlain, E. H. (1933) The Theory Monopolistic Competition (Cambridge, MA, Harvard University Press).

Clark, J. B. (1899a) The Distribution of Wealth: a theory of wages, interest and profits (New York, Macmillan).

Clark, J. B. (1899b) Natural divisions in economic theory, Quarterly Journal of Economics, 13, 187-203.

Coase, R. H. (1937) The nature of the firm, in: The Firm, the Market, and the Law (Chicago, University of Chicago Press, 1988).

Coase, R. H. (1960) The problem of social cost, in: The Firm, the Market, and the Law (Chicago, University of Chicago Press, 1988).

Coase, R. H. (1975) Marshall on method, in: Essays on Economics and Economists (Chicago, University of Chicago Press, 1994).

Coase, R. H. (1978) Economics and contiguous disciplines, Journal of Legal Studies, 7, pp. 201-211.

Coase, R. H. (1988) The Firm, the Market, and the Law (Chicago, University of Chicago Press). 
Coase, R. H. (1991) The nature of the firm: influence, in: O. Williamson \& S. Winter (Eds) The Nature of the Firm: origins, evolution and development (New York, Oxford University Press).

Coase, R. H. (1995) My evolution as an economist, in: W. Breit \& R. W. Spencer (Eds) Lives of the Laureates: thirteen Nobel economists, 3rd edn (Cambridge, MA, MIT Press).

Gunning, J. P. (2000a) Roy Cordato's 'Austrian' critique of Coase on social cost, Review of Austrian Economics, 13, pp. 175-192.

Gunning, J. Patrick. (2000b) The property system in Austrian economics, Review of Austrian Economics, 13, pp. 209-220.

Hsiung, B. (2001) A methodological comparison of Ronald Coase and Gary Becker, American Law and Economics Review, 3, pp. 186-198.

Robbins, L. (1932) An Essay on the Nature and Significance of Economic Science (London, Macmillan).

Slater, M. (1980) Forward, in: E. Penrose, The Theory of Economic Growth of the Firm, 2nd edn (White Plains, M.E. Sharpe).

Zerbe, R. O. \& Medema, S. G. (1997) Ronald Coase, the British Tradition, and the future of economic method, in: S. G. Medema (Ed.) Coasean Economics (Boston, Kluwer). 
Copyright of Review of Political Economy is the property of Carfax Publishing Company and its content may not be copied or emailed to multiple sites or posted to a listserv without the copyright holder's express written permission. However, users may print, download, or email articles for individual use. 